\title{
Epilepsy in Childhood and Adolescence
}

Bernd A. Neubauer, Stephanie Groß, Andreas Hahn

\section{SUMMARY}

Introduction: More than $3 \%$ of the total population will suffer from epilepsy at some time during their lives. One quarter of newly diagnosed cases worldwide are children. With optimal treatment, around $70 \%$ will enter remission. In the long run, antiepileptic drugs can be discontinued in almost half of affected individuals. Most patients with epilepsy undergo normal cognitive development. This relatively good prognosis contrasts with persistent public stigma surrounding the condition.

Methods: selective literature review.

Results: A classification of epileptic seizures and epileptic syndromes is provided by the International League Against Epilepsy (ILAE). Epilepsies are mainly split into symptomatic forms (i.e. those with a recognizable cause) and idiopathic forms, which result from a genetic predisposition and imply no other pathology aside from epilepsy.

The classification of epilepsy syndromes is based on assumed etiology, and seizure symptomatology.

Drug therapy is usually started after a second unprovoked seizure. The best possible seizure control, continuation of a successful school career, and preservation of a stable family situation are equally important therapeutic aims.

Dtsch Arztebl Int 2008; 105(17): 319-28

DOI: 103238/arztebl.2008.0319

Key words: childhood epilepsy, febrile seizures, seizure symptoms, medical treatment, seizure interval
Abteilung Neuropädiatrie, Sozialpädiatrie und Epileptologie, Zentrum Kinderund Jugendmedizin, Universitätsklinikum Gießen und Marburg GmbH: Prof. Dr. med. Neubauer, Dr. med. Groß, Dr. med. Hahn

\begin{abstract}
pilepsy is defined as the repeated occurrence of unprovoked epileptic seizures. The most common type of epileptic seizure occurring in childhood, however, is the febrile seizure. Febrile seizures are occasional seizures provoked by an elevation of body temperature; they do not indicate the presence of epilepsy, even if they occur repeatedly.

The learning objectives of this article are:

- being able to classify different types of seizures and epilepsy syndromes;

- becoming acquainted with the fundamentals of pharmacotherapy.
\end{abstract}

\section{Epidemiology}

The prevalence of epilepsy in childhood is approximately $0.5 \%$. In industrialized countries, an average of about 50 per 100000 children newly develop epilepsy each year. Children account for $25 \%$ of all new cases of epilepsy (1).

\section{Classification}

Epilepsy syndromes are classified mainly on the basis of their etiology and seizure manifestations. The individual seizure types are classified, and the diagnosis of each epilepsy syndrome is based on the seizure type(s) occurring in the syndrome and on its presumed etiology. Widely used classification systems were published in 1981 and 1989 and again just recently by the International League Against Epilepsy (ILAE, www.ilae-epilepsy.org) (2). An epilepsy syndrome is called idiopathic if it is of genetic origin and the affected individuals are otherwise neurologically normal. An epilepsy syndrome is called symptomatic if it has a documented cause, and presumed symptomatic (earlier: cryptogenic) if an underlying cause seems probable but has not (yet) been definitively identified (2). Symptomatic epilepsies can be caused either by a lesion (e.g., trauma, tumor, infection, or malformation) or by a systemic genetic illness (Box 1). The most relevant

\section{Epidemiology}

In industrialized countries, an average of approximately 50 per 100,000 children per year newly develop epilepsy each year. 


\section{BOX 1}

\section{Some genetic diseases that are commonly associated with epilepsy}

- Treatable metabolic diseases

- Vitamin B6 and folic acid-dependent seizures

- Biotinidase deficiency

- Glucose transporter deficiency

- Creatine deficiency syndrome

- Mitochondrial encephalopathies

- Urea cycle disorders

- Type I glutaraciduria

- Non-ketotic hyperglycemia

- Progressive myoclonus epilepsies

- Neuronal ceroid lipofuscinoses (mainly CLN 2)

- Myoclonus epilepsy with ragged red fibers

- Type I sialidosis

- Phakomatoses

- Tuberous sclerosis

- Sturge-Weber syndrome

- Ito syndrome

- Disorders of cortical development

- Lissencephaly

- Focal cortical dysplasia

- Subcortical band heterotopia

- Bilateral periventricular nodular heterotopia

- Chromosomal syndromes

- Angelman syndrome

- Rett syndrome

- PEHO syndrome

- Aicardi syndrome

- Wolf-Hirschhorn syndrome

\section{Accompanying illnesses}

About $70 \%$ of all children with epilepsy undergo normal cognitive development. On the other hand, reduced intelligence (IQ <70) is the most common comorbidity of children with epilepsy. Other common accompanying conditions, as demonstrated by epidemiologic studies, are cerebral palsy, hydrocephalus, tuberous sclerosis, and Sturge-Weber syndrome (4).

\section{Febrile seizures}

A febrile seizure, as defined by the ILAE, is an epileptic seizure occurring after the first month of life in the setting of a febrile illness that is not due to an infection of the central nervous system, usually with a body temperature exceeding $38^{\circ} \mathrm{C}$. Symptomatic seizures and seizures that occur after previous seizures in the neonatal period or previous afebrile seizures are, by definition, not considered febrile seizures (5).

Febrile seizures are called simple when

- they are generalized tonic-clonic seizures,

- they last less than 15 minutes, and

- they occur only once in a 24-hour period.

About $70 \%$ of all febrile seizures are simple; they are usually generalized tonic-clonic ("grand mal") seizures lasting about three minutes. Once the seizure is over, there is often a period of postictal sleep.

The pathophysiology of febrile seizures is not understood in detail. Age, fever (usually due to a banal infectious disease), and genetic predisposition are the main factors influencing them. About $3 \%$ of all children have a febrile seizure before age 7 ; the affected children are usually normally developed and are usually aged 3 months to 5 years. The prognosis of simple febrile seizures is very good, even if they occur more than once. The child's psychomotor development is unharmed, and the risk of epilepsy is only mildly elevated, from $0.5 \%$ to about 3\% (6).

(i.e., common) idiopathic epilepsy syndromes seen in everyday clinical practice come about through a complex interaction of multiple genetic factors and the modifying effects of environmental factors. In recent years, defects of various voltage-dependent and ligand-mediated ion channels have been demonstrated in a large number of epilepsy syndromes (often through the genetic study of extended pedigrees) (table 1). Thus, most types of idiopathic epilepsy are now known to belong to the class of ion channel diseases, which also includes the paroxysmal neuromuscular disorders (3).

\section{Febrile seizures}

- About $3 \%$ of all children have a febrile seizure before age 7 .

\section{The differential diagnosis and diagnostic evaluation of febrile seizures}

$1 \%$ to $3 \%$ of all apparent febrile seizures in childhood are, in fact, the initial manifestation of meningoencephalitis. In infancy and early childhood, the other typical clinical features of meningitis may be lacking. It follows that CSF examination should be performed in all children under 1 year of age, and generally also in children under the age of 18 months. The same holds for antibiotic treatment before lumbar puncture in each age group. From the age of 5 years onward, a febrile seizure
The treatment of febrile seizures

Maintenance pharmacotherapy is generally not indicated after a febrile seizure.

- Febrile seizures are usually self-limiting, generalized tonic-clonic seizures (grand mal seizures) lasting ca. 3 minutes. 
is no longer the leading element in the differential diagnosis of an epileptic seizure occurring in the setting of a fever. In infancy and early childhood, herpes encephalitis often manifests itself in the same manner as a complicated febrile seizure. If the clinical decision is made to perform a lumbar puncture, blood should also be drawn so that the sodium, calcium, and glucose concentrations can be measured. EEG and neuroimaging are not required in the evaluation of simple febrile seizures (6).

\section{The treatment of febrile seizures and the prevention of their recurrence}

If a febrile seizure does not terminate spontaneously within five minutes, it must be interrupted with medication. The parents of children with febrile seizures or epilepsy should be provided with a rapidly acting benzodiazepine preparation that can be given rectally or orally to abort a seizure (Box 2 ). When given in the correct dose, such preparations do not cause respiratory depression (7). Maintenance therapy is generally not indicated.

The overall rate of recurrence of febrile seizures is about $30 \%$. In order to prevent further febrile seizures in children with a febrile illness, antipyretic measures are often recommended. This is certainly reasonable in a pragmatic sense and improves the child's general wellbeing, but it has been well documented that doing so does not reduce the risk of recurrence of a febrile seizure to any significant extent. Intermittent diazepam prophylaxis at a dose of $0.33 \mathrm{mg}$ per $\mathrm{kg}$ body weight per day for as long as the child is febrile has been found to be effective (8). This treatment should only be given only after repeated febrile seizures, however, and should be maintained for no longer than 72 hours. The dose of diazepam should be reduced, or the medication should be discontinued, in the event of side effects such as marked sedation or unsteady gait.

\section{The major age-related epilepsy syndromes of children and adolescents}

\section{- Onset in the first year of life}

The main causes of symptomatic epilepsy in the neonatal period are hypoxic-ischemic encephalopathy, congenital and neonatal infections, acute metabolic disturbances (glucose, electrolytes), and cortical abnormalities (infarct, hemorrhage, malformation). Idiopathic epilepsy syndromes are rare in neonates. Pyridoxine-,

\section{TABLE 1}

\section{The most important genetic defects in idiopathic epilepsies \\ (including allelic diseases*1)}

\begin{tabular}{|c|c|}
\hline Gene & Epilepsy syndrome \\
\hline \multicolumn{2}{|c|}{ Sodium channels } \\
\hline SCN1A & GEFS+, SMEI \\
\hline SCN2A & BFNIS, GEFS+ \\
\hline SCN1B & GEFS+ \\
\hline \multicolumn{2}{|c|}{ Potassium channels } \\
\hline KCNQ2 & BFNS \\
\hline KCNQ3 & BFNS \\
\hline KCN1A & $\mathrm{PE}, \mathrm{EA1}$ \\
\hline \multicolumn{2}{|c|}{ Chloride channels } \\
\hline CLCN2 & IGE \\
\hline \multicolumn{2}{|c|}{ GABA receptors } \\
\hline GABRA1 & ADJME \\
\hline GABRA2 & CAE, FS, GEFS+ \\
\hline GABRD & GEFS+ \\
\hline \multicolumn{2}{|c|}{ Acetylcholine receptors } \\
\hline CHRNA4 & ADNFLE \\
\hline CHRNB2 & ADNFLE \\
\hline \multicolumn{2}{|c|}{ Calcium channels } \\
\hline CACNA1H & CAE \\
\hline CACNB4 & IGE, JME \\
\hline CACNA1A & IGE, EA2, SCA6 \\
\hline \multicolumn{2}{|c|}{ Non-ion-channel genes } \\
\hline LG11 & ADPEAF (=ADLTE) \\
\hline EFHC1 & JME \\
\hline MASS1 & FS?, GEFS? \\
\hline
\end{tabular}

*1 after (3).

GEFS, generalized epilepsy with febrile seizures; SMEl, severe myoclonic epilepsy of infancy; BFNIS, benign familial neonatal-infantile seizures; BFNS, benign familial neonatal seizures; IGE, spectrum of idiopathic generalized epilepsies; ADJME, autosomal dominant juvenile myoclonic epilepsy; CAE, childhood absence epilepsy (pyknolepsy); FS, febrile seizures;

ADNFLE, autosomal dominant nocturnal frontal lobe epilepsy; ADPEAF, autosomal dominant partial epilepsy with auditory symptoms

PE, partial epilepsy; $E A$, episodic ataxia; SCA6, spinal-cerebellar ataxia type 6 .
Initial manifestation of meningoencephalitis $1-3 \%$ of all febrile seizures in childhood are the initial manifestation of meningoencephalitis. In infancy and early childhood, herpes encephalitis often manifests itself as a complicated febrile seizure.

\section{West syndrome}

West syndrome, a condition with a poor prognosis, is characterized by the triad of infantile spasms, hypsarrhythmia in the EEG, and developmental regression. 
pyridoxal-phosphate-, and folinic acid-dependent seizures usually begin in the neonatal period and are often associated with a so-called suppression-burst pattern in the EEG. These metabolic diseases are rare, but should always be included in the differential diagnosis because of their high prognostic relevance. Treatment with the missing vitamin leads to freedom from seizures, or at least to significant improvement (9).

\section{Benign partial epilepsy of childhood (etiology: idiopathic)}

The seizures begin between the 3rd and 20th month of life. They usually consist of a temporary cessation of activity with movements, rolling of the eyes, and focal clonus, sometimes followed by secondary generalization. They are occasionally accompanied by crying or screaming. These children develop normally and have a normal interictal EEG (10).

\section{Dravet syndrome}

This is a syndrome of severe myoclonic epilepsy in infancy. It manifests itself in the first year of life, in an infant whose development has been normal up to that time, with febrile or afebrile generalized tonic-clonic seizures and unilateral seizures that usually occur on alternating sides. The prognosis with regard to freedom from seizures, and with regard to cognitive development, is very unfavorable (11). A defect in the SCN1A gene (a sodium channel gene) can be demonstrated in some $60 \%$ of the affected children (12). If myoclonic seizures are not a prominent feature, this type of epilepsy is designated as early childhood epilepsy with generalized, tonic-clonic seizures and alternating hemi-grand mal (13). The marked dependence of the seizures on fever and infectious illnesses is a characteristic feature of this type of epilepsy.

\section{West syndrome (etiology: symptomatic or cryptogenic)}

West syndrome typically arises in infants aged 1 to 7 months. Its most common causes are perinatal asphyxia, CNS malformations, and tuberous sclerosis. West syndrome is characterized by the triad of infantile spasms, hypsarrhythmia in the EEG, and developmental regression. The most common type of seizure is a symmetrical flexion or extension spasm of the extremities (infantile spasms). The German expression "Blitz-Nick-Salaam" (BNS) seizures also refers to two other ictal manifestations that are seen in this disease: "Blitz" (lightning) attacks, i.e., powerful myoclonic jerks, and "Nick" (nodding) attacks, i.e., short, often mild (myolonic) flexions of the head. The prognosis of symptomatic West syndrome with regard to freedom from seizures and cognitive development is unfavorable.

\section{- Onset in early childhood (ca. until age 5) \\ Early childhood absence epilepsy (etiology: idiopathic)}

In the German-speaking countries, three separate entities are distinguished: early childhood absence epilepsy with onset in the first four years of life, childhood absence epilepsy, and juvenile absence epilepsy. The international classification, on the other hand, combines the first two of these into a single entity.

\section{Doose syndrome (etiology: idiopathic)}

This syndrome consists of myoclonic-astatic epilepsy arising between the second and fifth years of life. The disorder usually begins with febrile or afebrile generalized tonic-clonic seizures; often, explosive myoclonic-astatic seizures begin to occur a few weeks later. Non-convulsive status epilepticus, sometimes giving the impression of stupor, is typical. The prognosis is relatively good in about $50 \%$ of cases if the seizures can be brought under control rapidly and consistently (14).

\section{Lennox-Gastaut syndrome (etiology: symptomatic or cryptogenic)}

In this epilepsy syndrome, a CNS malformation or cortical lesion is demonstrable in about two-thirds of cases. Epilepsy usually arises between the second and sixth years of life. Tonic seizures, atypical absences (absent states with mild motor or autonomic phenomena), and drop attacks are typical. The vast majority of patients (ca. 90\%) are intellectually impaired. Tonic seizures are required for the diagnosis. Lennox-Gastaut syndrome is nearly always intractable.

\section{- Onset in childhood (ca. until age 11) Absence epilepsy of childhood, so-called pyknolepsy (etiology: idiopathic)}

This disease usually arises in children of normal intelligence aged five to eight years. The absences last 5 to 30 seconds. In pyknolepsy, up to 100 such attacks can occur per day.

The longer an absence lasts, the more likely it is to be accompanied by motor or autonomic manifestations (such as blinking or pallor). In a small percentage of cases, absence epilepsy manifests itself as non-convulsive

\section{Absence seizures}

Absence seizures are generalized seizures consisting of a brief cessation of activity. They are often confused with "daydreaming." The EEG reveals a $3-\mathrm{Hz}$ spike-and-wave pattern.

\section{Rolandic epilepsy}

Nocturnal focal sensorimototor seizures of the perioral region are typical. 
status epilepticus (earlier designated "petit mal status epilepticus"). These patients are often markedly slowed for hours, appear disoriented, and react only to a limited degree to verbal stimuli.

\section{Rolandic epilepsy (etiology: idiopathic)}

This disorder is a benign, idiopathic partial epilepsy with centrotemporal spikes in the EEG. It occurs in about 1 of every 12000 children and is thus the most common type of childhood epilepsy after absence epilepsy. The majority of patients have a first seizure between the sixth and ninth years of life. Sensorimotor focal seizures of the perioral area are characteristic; these consist of paresthesiae of the lips, tongue, and palate that are more pronounced on one side and perioral myoclonic, clonic, and tonic seizures (twitching and pulling of the lips and cheeks). The affected child cannot swallow or speak during a seizure. Marked salivation occurs. By the time they reach age 12 to 14 , nearly all affected children are free of seizures, either with or without medication.

In rare cases (perhaps $1 \%$ to $3 \%$ ), there is marked activation of the typical EEG changes of rolandic epilepsy during sleep, ranging all the way to so-called bioelectric status epilepticus. These children develop the clinical picture of an atypical idiopathic partial epilepsy (so-called pseudo-Lennox-Gastaut syndrome). The prognosis of the epilepsy itself remains good, but caution should be exercised in predicting the developmental prognosis (15).

\section{- Beginning in adolescence \\ (from ca. age 12 onward) \\ Juvenile absence epilepsy (etiology: idiopathic)}

The absences in this condition are in principle no different from those of childhood absence epilepsy, although they usually occur less frequently. Over the course of the disease, rare generalized tonic-clonic seizures also arise in about $80 \%$ of the affected persons.

\section{Epilepsy with isolated, generalized tonic-clonic seizures (etiology: idiopathic)}

This disease is also called "epilepsy with grand mal seizures on awakening." The seizures usually arise within two hours of awakening. The peak prevalence of this condition is around the age of 15 years. The seizure frequency is usually low. Sleep deprivation, alcohol consumption, or severe emotional stress often precipitates the seizures.

\section{Janz syndrome}

Myoclonus of the arms and hands occurs in the morning. In the later course of the illness, patients suffer from generalized tonic-clonic seizures. The prognosis under treatment is good, but treatment must be provided for life.

\section{Juvenile myoclonic epilepsy or Janz syndrome (etiology: idiopathic)}

This epilepsy syndrome is common (5\% to $10 \%$ of all patients with epilepsy) and effects children and adolescents of normal intelligence. It usually begins between the ages of 12 and 17. Its cardinal manifestation is shortlasting myoclonus of the shoulders and arms arising in the morning, often shortly after awakening. This "twitching" leads the affected persons to spill beverages or drop objects and is often initially misinterpreted as a tic or an expression of nervousness. In about $90 \%$ of cases, generalized tonic-clonic seizures also appear in the later course of the disease; these sometimes develop out of the myoclonus episodes. Complete freedom from seizures can usually be achieved with medication, but this must be given for life.

\section{Age-independent epilepsy syndromes Focal epilepsy syndromes}

These epilepsy syndromes can occur at any age as the result of focal cortical disturbances of various types. Migration disorders, dysontogenetic tumors, postinfectious sclerosis, and, less commonly, vascular processes are among the typical causes. Focal seizures can occur without any impairment of consciousness (simple partial seizures) or with some degree of impairment of consciousness (complex partial seizures). A transition to a secondarily generalized tonic-clonic seizure is also possible. The younger the affected child is, the more markedly the seizure manifestations may differ from the typical picture.

\section{Temporal lobe epilepsy}

Prolonged or complicated febrile seizures and febrile status epilepticus are a feature of the history in $30 \%$ of (adult) patients with medically intractable temporal lobe epilepsy. Looked at the other way, however, the risk of developing temporal lobe epilepsy is not significantly elevated in a child who has sustained a febrile seizure. Mesial temporal lobe epilepsy is the most common type. The average seizure duration is about two minutes. Characteristically, the seizure begins with an aura. Patients report a burning sensation ascending from the stomach (a so-called epigastric aura), a feeling of heat, or just a diffuse state of anxiety. Oro-alimentary automatisms (lip-smacking or chewing) and manual automatisms (picking at clothes) are also typical. The onset and offset of the seizure are often not sharply demarcated (16).

\section{Temporal lobe epilepsy}

Mesial temporal lobe epilepsy is the most common variety. The individual seizures usually last about two minutes. They are typically introduced by an aura. 


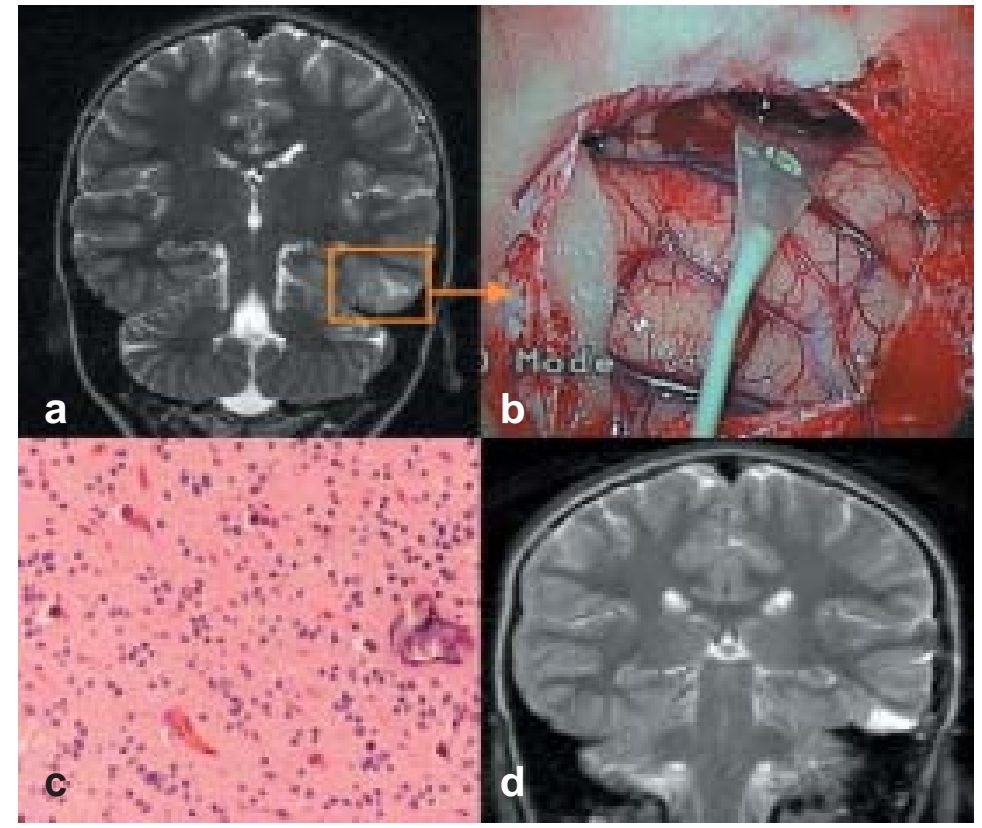

Figure: Diagnostic images of a 12-year-old boy with temporal lobe seizures: a) preoperative MRI scan, b) intraoperative photograph, c) histopathological preparation and d) postoperative MRI scan. The preoperative MRI scan (Prof. Traupe and Dr. Hügens-Penzel, Giessen) shows an area in the inferior temporal gyrus measuring ca. $23 \mathrm{~mm}$ that has an inhomogeneous, abnormal architecture and does not take up contrast medium. The intraoperative image (PD Dr. Jödicke, Giessen) was taken during electrocorticocraphy (Prof. Rosenow and Prof. Hamer, Marburg) revealing epileptogenic activity not only over the lesion itself, but also medial and anterior to it. The histopathological preparation (Prof. Schachenmayr and

Prof. Kuchelmeister, Giessen) reveals an oligodendroglioma, WHO grade II. The postoperative MRI shows the tissue defect after resection.

\section{BOX 2}

\section{Pharmacological interruption of seizures in childhood *1}

- Interruption of seizures with medications given per os or per rectum (the indicated doses are valid for body weight up to $40 \mathrm{~kg}$ )

- Diazepam rectal solution $5 \mathrm{mg}$ (up to $20 \mathrm{~kg}$ body weight [BW]) or $10 \mathrm{mg}$ (more than $20 \mathrm{~kg}$ body weight), or

- Lorazepam $1 \mathrm{mg}$ (10 to $25 \mathrm{~kg}$ body weight) or $2.5 \mathrm{mg}$ (25 kg or more body weight)

- Stepwise algorithm for the interruption of seizures with intravenous medication

- Lorazepam 0.05-0.1 mg/kg BW, repeat as needed, or Diazepam $0.20 \mathrm{mg} / \mathrm{kg} \mathrm{BW}$, repeat as needed

- Phenobarbital 10-20 mg/kg BW over 5 (to 10) minutes

- Phenytoin 10-20 mg/kg BW over 20 to 30 minutes

*1 Evidence class III; (26).

\section{Frontal lobe epilepsy}

Frontal lobe seizures often begin and end abruptly. Patients usually regain orientation rapidly after a seizure. The seizures often occur frequently right from the onset of the condition, and they often arise in sleep. Clusters of increased seizure frequency are also typical. The seizure manifestations are of various different types. Asymmetrical tonic seizures are characterized by uni- or bilateral "postural" arm-raising and headturning, while the patient generally remains conscious. Focal clonic seizures consist of unilateral clonus of the arm, the hand, or the face, with speech arrest and versive movements. Consciousness is generally preserved in this type of seizure as well. Hypermotor seizures are associated with impaired consciousness and with storms of movement affecting the entire body, often of bizarre types, such as pedaling, kicking, etc. (17).

\section{Occipital lobe epilepsy}

Simple and complex focal seizures with visual symptoms are characteristic. Positive visual phenomena, such as phosphenes (shining geometrical structures), and negative ones, such as scotomata or gray points and areas in the visual field, represent simple hallucinations and are the most common types of visual symptom. Occipital seizures spread rapidly and can thus occasionally produce symptoms that are typical of seizures arising in the frontal or temporal lobe (18).

\section{The diagnostic evaluation of children and adolescents with epilepsy}

Meticulous history-taking should include inquiry about unexplained falls, absent states, and morning clonus. Furthermore, a complete pediatric medical and neurological examination should be performed for the exclusion of other underlying conditions. If possible, the patient's parents should be asked to record seizure-like events with a digital or video camera. Involuntary loss of urine is a feature of epileptic seizures, but also of syncope. After a first seizure, it is always proper to draw blood for the determination of the serum glucose, sodium, and calcium concentrations, and also of the serum magnesium concentration in infants; in patients that cannot be adequately clinically examined (postictal sleep, neonates, infants, small children), these tests are indispensable. EEG is the most informative instrument for the diagnostic evaluation of epileptic seizures. The recording of a sleep phase and the use of provocative

\section{A first afebrile seizure \\ A first afebrile seizure should be evaluated with EEG and, with rare exceptions, MRI.}

Afebrile, generalized tonic-clonic seizures These subside spontaneously within about three minutes in $70 \%$ of cases occurring in older children. Pharmacological intervention according to the stepwise algorithm should be initiated after five minutes at the latest. 
TABLE 2

\section{Pharmacotherapy of epilepsy syndromes}

\begin{tabular}{|c|c|c|c|}
\hline Epilepsy syndrome & Medications of first choice & Medications of second choice & $\begin{array}{l}\text { Potentially seizure- } \\
\text { provoking medications }\end{array}$ \\
\hline Benign partial epilepsy of childhood & Carbamazepine (low dose) & Phenobarbital (low dose) & - \\
\hline Dravet syndrome & $\begin{array}{l}\text { Valproate, topiramate, } \\
\text { bromides }\end{array}$ & Benzodiazepines & $\begin{array}{l}\text { Phenytoin, carbamazepine, } \\
\text { oxcarbazepine, lamotrigine }\end{array}$ \\
\hline Early childhood grand mal epilepsy & Valproate, lamotrigine & Topiramate, primidone & $\begin{array}{l}\text { Phenytoin, carbamazepine, } \\
\text { oxcarbazepine }\end{array}$ \\
\hline West syndrome & $\begin{array}{l}\text { ACTH, valproate, } \\
\text { sulthiame, vigabatrin? }\end{array}$ & $\begin{array}{l}\text { Topiramate, lamotrigine, } \\
\text { felbamate, zonisamide, } \\
\text { clonazepam }\end{array}$ & - \\
\hline Absence epilepsies & $\begin{array}{l}\text { Valproate, ethosuximide, } \\
\text { lamotrigine (all III)*1 }\end{array}$ & Levetiracetam & $\begin{array}{l}\text { Phenytoin, oxcarbazepine, } \\
\text { carbamazepine, barbiturates, } \\
\text { pregabalin, tiagabine }\end{array}$ \\
\hline Myoclonic-astatic epilepsy & $\begin{array}{l}\text { Valproate, } \\
\text { ethosuximide, } \\
\text { lamotrigine }\end{array}$ & $\begin{array}{l}\text { Primidone, } \\
\text { phenobarbital, } \\
\text { benzodiazepines }\end{array}$ & $\begin{array}{l}\text { Phenytoin, oxcarbazepine, } \\
\text { carbamazepine }\end{array}$ \\
\hline Lennox-Gastaut syndrome & $\begin{array}{l}\text { Valproate, topiramate, lamotrigine, } \\
\text { felbamate, levetiracetam, zonisamide }\end{array}$ & Primidone, phenobarbital & Benzodiazepines \\
\hline Rolandic epilepsy & $\begin{array}{l}\text { Sultiame, gabapentin, } \\
\text { valproate }(I I I)^{* 1}\end{array}$ & Clobazam, levetiracetam? & $\begin{array}{l}\text { Phenytoin, carbamazepine, } \\
\text { oxcarbazepine }\end{array}$ \\
\hline Grand mal epilepsy on awakening & Valproate $(\mathrm{III})^{*_{1}}$ & Lamotrigine, levetiracetam & $\begin{array}{l}\text { Phenytoin, carbamazepine, } \\
\text { oxcarbazepine, tiagabine }\end{array}$ \\
\hline Juvenile myoclonic epilepsy & $\begin{array}{l}\text { Valproate, lamotrigine, levetiracetam, } \\
\text { topiramate }\end{array}$ & Primidone, benzodiazepines & $\begin{array}{l}\text { Phenytoin, carbamazepine, } \\
\text { oxcarbazepine, } \\
\text { gabapentin, tiagabine }\end{array}$ \\
\hline Focal (lesional) epilepsies & 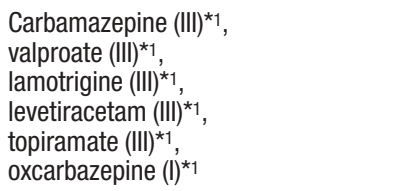 & Phenytoin, primidone, benzodiazepines & - \\
\hline
\end{tabular}

*1 Number in parentheses, evidence class modified after (20). Where not indicated, evidence class IV.

techniques such as photic stimulation and hyperventilation double the sensitivity of EEG for epilepsy in children. An MRI scan of the brain should be performed in all new cases of epilepsy to determine whether a mass lesion, a cortical malformation, or a phakomatosis is present (figure). Exceptions can be made to this rule in cases of

- 3-Hz spike-wave absences,

- rolandic epilepsy, or

- juvenile myoclonic epilepsy with typical manifestations.

\section{Pharmacotherapy}

Monotherapy is desirable as a rule.
The MRI scan must be obtained on an emergency basis only if the patient has focal neurologic deficits or an impairment of consciousness that does not rapidly resolve after the seizure (i.e., within one or two hours). In the first year of life, ultrasonography of the brain can be performed first, and an MRI scan at some later time (figure). A lumbar puncture is usually not indicated for the evaluation of a first afebrile seizure in a child beyond early infancy (i.e., aged six months or older). Neurometabolic diseases presenting exclusively with epileptic seizures are seen almost exclusively in the neonatal period or in infancy (19). 


\section{Seizure interruption}

$70 \%$ of afebrile, generalized tonic-clonic seizures occurring in later childhood subside spontaneously within about three minutes. If a seizure lasts longer than five minutes, a benzodiazepine drug should be given. If this does not abort the seizure within a further five minutes, benzodiazepine administration should be repeated. After another five or ten minutes, either phenobarbital or phenytoin must be given intravenously (Box 2). If the seizure lasts 30 minutes or longer, status epilepticus is said to be present. This is also the case if there has been a series of seizures over a total period of 30 minutes or longer without recovery of consciousness between them. If an epileptic seizure fails to improve after 15 to 20 minutes, further treatment should be delivered in an intensive-care setting.

\section{Maintenance pharmacotherapy}

The medical treatment of an epilepsy syndrome (table 2 ) should be in the hands of a trained specialist, because the treatment of the epilepsy syndrome and the manner in which the patient is counseled will have a decisive effect on the life of the patient and the patient's family. The scientific evidential basis for most of the medications that are used (successfully) today to treat epilepsy in children and adolescents is rather sparse. The time and expense required to carry out prospective trials with appropriate controls for age, type of epilepsy syndrome, and developmental state, including study of the longterm course under treatment, would be enormous, indeed exceeding the time for which newly introduced medications are protected by patent (20).

Maintenance therapy is generally considered indicated after the occurrence of at least two (unprovoked) epileptic seizures or a single episode of status epilepticus. If epilepsy cannot be brought into remission with a medication of first choice, the patient should be referred to an epilepsy center for further treatment (evidence class III).

\section{Epilepsy surgery}

Epilepsy surgery should be considered early on for children with focal (symptomatic), medically intractable epilepsy, usually after the third medication to be administered has not had the desired effect. The advances that have been made in epilepsy surgery are among the more remarkable successes of modern medicine. In many cases, freedom from seizures or a marked reduction of seizure frequency can be achieved, along with improved development and better cognitive function- ing. This is true for children in all age groups (21). Success is most frequent in children with lesional temporal lobe epilepsy: about $75 \%$ become totally free of seizures after the surgical procedure.

Two alternative methods of treatment that are already in use for medically intractable and inoperable patients are vagus nerve stimulation and a ketogenic diet (22, 23). The evidence for their effectiveness is derived from case series.

\section{Course and prognosis}

The prognosis of epilepsy in the individual case depends mainly on the type of epilepsy syndrome that is present. Overall, remission is achieved in about $70 \%$ of children with epilepsy. In just over half of all children with epilepsy, the antiepileptic medications can eventually be permanently discontinued.

\section{Epilepsy and school}

Approximately two-thirds of all children with epilepsy are normally intelligent. It would be desirable for the same fraction to finish school, but this is, unfortunately, not the current reality, for a number of reasons. Children with epilepsy are more likely than their normal classmates to suffer from partial performance impairments and attention deficits (24). Psychological testing can be used to determine the optimal form of schooling for the individual child and to detect any partial performance impairments that may be present. Failure in school should then be preventable with the timely provision of treatment and scholastic assistance. As a rule of thumb, it can be said that an antiepileptic drug given in a moderate dose does not impair a child's performance in school. It should also be mentioned that treatment with stimulants is usually possible, without any problem, in children who have both medically controlled epilepsy and a concomitant attention-deficit disorder (ADD or ADHD).

\section{Conflict of Interest Statement \\ The authors state that they have no conflict of interest as defined by the guidelines of the International Committee of Medical Journal Editors.}

Manuscript received on 13 June 2007; revised version accepted on 19 September 2007.

Translated from the original German by Ethan Taub, M.D.

\section{REFERENCES}

1. Camfield CS, Camfield PR, Gordon K, Wirrell E, Dooley JM: Incidence of epilepsy in childhood and adolescence: a population-based study in Nova Scotia from 1977 to 1985. Epilepsia 1996; 37: 19-23.

\section{The goals of pharmacological maintenance treatment \\ Freedom from seizures, the successful \\ continuation of schooling or vocational training, and the maintenance of a stable family situation are equally important goals of treatment.}

\section{School performance}

Monotherapy against seizures in a moderate dose does not affect school performance. Stimulant therapy can usually be provided without any problem to children with well-controlled epilepsy. 
2. Engel J, Jr: Classification of epileptic disorders. Epilepsia 2001; 42 : 796-803.

3. Mulley JC, Scheffer IE, Harkin LA, Berkovic SF, Dibbens LM: Susceptibility genes for complex epilepsy. Hum Mol Genet 2005;14: 243-9.

4. Pellock JM: Understanding co-morbidities affecting children with epilepsy. Neurology 2004; 62: 17-23.

5. Guidelines for epidemiologic studies on epilepsy. Commission on Epidemiology and Prognosis, International League Against Epilepsy. Epilepsia 1993; 34: 592-6.

6. Waruiru C, Appleton R: Febrile seizures: an Update. Arch Dis Child 2004; 89: 751-6

7. Knudsen FU: Rectal administration of diazepam in solution in the acute treatment of convulsions in infants and children. Arch Dis Child 1979; 54: 855-7.

8. Rosman NP, Colton T, Labazzo J et al.: A controlled trial of diazepam administered during febrile illnesses to prevent recurrence of febrile seizures. N Engl J Med 1993; 329: 79-84.

9. Leonard JV: Recent advances in amino acid and organic acid metabolism. J Inherit Metab Dis 2007; 30: 134-8.

10. Okumura A, Watanabe K, Negoro T, Hayakawa F, Kato T, Natsume J: The clinical characterizations of benign partial epilepsy in infancy. Neuropediatrics 2006; 37: 359-63.

11. Dravet C, Bureau M, Oguni H, Fukuyama Y, Cokar O: Severe myoclonic epilepsy in infancy: Dravet syndrome. Adv Neurol 2005; 95 71-102.

12. Ebach $\mathrm{K}$, Joos H, Doose H et al.: SCN1A mutation analysis in myoclonic astatic epilepsy and severe idiopathic generalized epilepsy of infancy with generalized tonic-clonic seizures. Neuropediatrics 2005; 36: 210-3.

13. Doose H, Lunau H, Castiglione E, Waltz S: Severe idiopathic generalized epilepsy of infancy with generalized tonic-clonic seizures. Neuropediatrics 1998; 29: 229-38.

14. Neubauer BA, Hahn A, Doose H, Tuxhorn I: Myoclonic-astatic epilepsy of early childhood - definition, course, nosography, and genetics. Adv Neurol 2005; 95:147-155.

15. Hahn A, Pistohl J, Neubauer BA, Stephani U: Atypical „benign“ partial epilepsy or pseudo-Lennox syndrome. Part I: symptomatology and long-term prognosis. Neuropediatrics 2001; 32: 1-8.

16. Engel J, Jr.: Introduction to temporal lobe epilepsy. Epilepsy Res 1996; 26: 141-50.

17. Kotagal P, Arunkumar G, Hammel J, Mascha E: Complex partial seizures of frontal lobe onset: statistical analysis of ictal semiology. Seizure 2003; 12: 268-81.

18. Taylor I, Scheffer IE, Berkovic SF: Occipital epilepsies: identification of specific and newly recognized syndromes. Brain 2003; 126 : 753-69.

19. Hirtz D, Ashwal S, Berg A et al.: Practice parameter: evaluating a first nonfebrile seizure in children: report of the quality standards subcommittee of the American Academy of Neurology, The Child Neurology Society, and The American Epilepsy Society. Neurology 2000; 55: 616-23

20. Glauser T, Ben-Menachem E, Bourgeois B et al.: ILAE treatment guidelines: evidence-based analysis of antiepileptic drug efficacy and effectiveness as initial monotherapy for epileptic seizures and syndromes. Epilepsia 2006; 47: 1094-120.

21. Loddenkemper T, Holland KD, Stanford LD, Kotagal P, Bingaman W, Wyllie E: Developmental outcome after epilepsy surgery in infancy. Pediatrics 2007; 119: 930-5.

22. Benifla M, Rutka JT, Logan W, Donner EJ: Vagal nerve stimulation for refractory epilepsy in children: indications and experience at The Hospital for Sick Children. Childs Nerv Syst 2006; 22: 1018-26.

23. Freeman JM, Kossoff EH, Hartman AL: The ketogenic diet: one decade later. Pediatrics 2007; 119: 535-43.

24. Dunn DW, Kronenberger WG: Childhood epilepsy, attention problems, and ADHD: review and practical considerations. Semin Pediatr Neurol 2005; 12: 222-8.
25. Aldenkamp AP, Arzimanoglou A, Reijs R, Van MS: Optimizing therapy of seizures in children and adolescents with ADHD. Neurology 2006; 67: 49-51.

26. Appleton R, Martland T, Phillips B: Drug management for acute tonic-clonic convulsions including convulsive status epilepticus in children. Cochrane Database Syst Rev 2002; CD001905.

\section{Corresponding author}

Prof. Dr. med. Bernd A. Neubauer

Leiter der Abteilung Neuropädiatrie, Sozialpädiatrie und Epileptologie

Feulgenstr. 12

35385 Giessen, Germany

Bernd.A.Neubauer@paediat.med.uni-giessen.de

For a case report please refer to www.aerzteblatt.de/cme/0805

\section{Further Information on GME}

This article has been certified by the North Rhine Academy for Postgraduate and Continuing Medical Education.

The Deutsches Ärzteblatt provides certified continuing medical education (CME) in accordance with the requirements of the Chambers of Physicians of the German federal states (Länder). CME points of the Chambers of Physicians can be acquired only through the Internet by the use of the German version of the CME questionnaire within 6 weeks of publication of the article. See the following website: www.aerzteblatt.de/cme.

Participants in the CME program can manage their CME points with their 15-digit "uniform CME number" (einheitliche Fortbildungsnummer, EFN). The EFN must be entered in the appropriate field in the www.aerzteblatt.de website under "meine Daten" ("my data"), or upon registration. The EFN appears on each participant's CME certificate.

The solutions to the following questions will be published in volume 25/2008.

The CME unit "Wounds: From Physiology to Dressings" (volume 13/2007) can be accessed until 9 May 2008.

For volume 21/2008 we plan to offer the topic "Bronchial Asthma."

Solutions to the CME questionnaire in volume 9/2008:

Kohnen T, Strenger A, Klaproth 0: Basic Knowledge of Refractive Surgery. 1b; 2b, 3c, 4d, 5e, 6c, 7b, 8c, 9a, 10b 
Please answer the following questions to participate in our certified Continuing Medical Education program. Only one answer is possible per question. Please select the answer that is most appropriate.

\author{
Question 1 \\ Which of the following is more consistent with \\ a complicated febrile seizure than with a simple \\ febrile seizure? \\ a) Age $>6$ months and $<5$ years \\ b) A generalized tonic-clonic seizure \\ c) A recurrent seizure with another febrile illness three \\ months later \\ d) A focal seizure \\ e) A seizure lasting 10 minutes
}

\section{Question 2}

A young mother brings her 8-month-old infant to the doctor's office because it had sustained an episode of twitching of the arms and legs, with unconsciousness, for several minutes while at home with a febrile illness $\left(39.2^{\circ} \mathrm{C}\right)$. The child is still febrile during the physical examination and is highly irritable. What should the doctor do next?

a) Prescribe maintenance anticonvulsant medication.

b) Give diazepam immediately.

c) Perform a lumbar puncture to rule out meningitis.

d) Take an appropriate history to rule out herpes encephalitis.

e) Initiate effective treatment to lower the child's temperature, as this will significantly reduce the risk of further febrile seizures.

\section{Question 3}

Which of the following characterizes West syndrome?

a) The rare occurrence of developmental disturbances.

b) Infantile spasms.

c) A defective sodium ion channel.

d) 3-Hz spike-and-wave paroxysms in the EEG.

e) An uncomplicated course under outpatient treatment.

Question 4

Which of the following is typical of childhood absence

epilepsy (pyknolepsy)?

a) Brief complex focal seizures.

b) Centrotemporal spikes in the EEG.

c) A high rate of medical intractability.

d) Usually, pre-existing mental retardation.

e) A high seizure frequency, with up to 100 seizures per day.

\section{Question 5}

Which of the following characterizes rolandic epilepsy?

a) Hypsarrhythmia in the EEG.

b) Worsening of epilepsy with puberty.

c) The occurrence of bioelectrical status epilepticus in sleep.

d) Sensorimotor focal seizures that often occur around the mouth.

e) More frequent occurrence of seizures upon awakening.

\section{Question 6}

Which of the following treatments is used to interrupt an acute seizure?

a) Lorazepam $0.1 \mathrm{mg} / \mathrm{kg} \mathrm{BW} \mathrm{p.0.}$

b) Phenobarbital $50 \mathrm{mg} / \mathrm{kg}$ BW as a slow IV push.

c) Phenytoin $0.5-0.75 \mathrm{mg} / \mathrm{kg}$ BW IV. d) Diazepam 5-6 mg/kg BW p.r.

e) Tetrazepam 3-4 mg/kg BW p.o.

Question 7

A 7-year-old girl is taken to the doctor after having an episode at school that may have been a seizure.

She is afebrile.

With what should the diagnostic evaluation begin?

a) An extensive history of the event (possible seizure) does not need to be obtained.

b) A thorough physical examination should be performed and a seizure history should be taken.

c) A sleep-deprived EEG and electromyography should be performed.

d) An MRI scan of the brain should be performed only if there is clinical reason to suspect a brain tumor.

e) A lumbar puncture should be performed to rule out herpes encephalitis.

Question 8

Which of the following are the medications of first choice in absence epilepsy?

a) Lamotrigine, carbamazepine, ethosuximide

b) Primidone, topiramate, benzodiazepines

c) Valproate, carbamazepine, ethosuximide

d) Ethosuximide, lamotrigine, valproate

e) Lamotrigine, valproate, primidone

Question 9

Myoclonic-astatic epilepsy is diagnosed in a 4-year-old boy. How should the child be treated?

a) A treatment of first choice is primidone.

b) A treatment of first choice is carbamazepine.

c) A treatment of first choice is valproate.

d) A treatment of first choice is surgical intervention.

e) A treatment of first choice is a ketogenic diet.

Question 10

How do children with epilepsy perform cognitively and in school?

a) $90 \%$ of children who have epilepsy in childhood need lifelong treatment with medications, with the resulting adverse consequences for their cognitive and scholastic performance.

b) If a child with epilepsy should additionally develop attention deficit-hyperactivity syndrome, the latter must not be treated with medication.

c) About $70 \%$ of children with epilepsy have cognitive deficits.

d) Only about $30 \%$ of children with epilepsy become seizure-free under treatment.

e) Treatment with a single anticonvulsant medication at a moderate dose generally does not affect a child's cognitive or scholastic performance. 


\section{Epilepsy in Childhood and Adolescence}

Bernd A. Neubauer, Stephanie Groß, Andreas Hahn

\section{Case illustrations}

\author{
Epilepsy in childhood and adolescence
}

- Example 1: A 9-year-old boy was presented to us because of absence states with eyelid fluttering that had been occurring multiple times each day for several weeks. The EEG revealed typical $3-\mathrm{Hz}$ spike-and-wave paroxysms that were activated by hyperventilation. The boy had had a febrile seizure at the age of 3 years; one week ago, he had an afebrile generalized tonic-clonic seizure. He was normally developed for age and the neurological examination and MRI revealed no abnormalities.

Typical absences were his dominant seizure type. Rare generalized tonic-clonic seizures occur in about $30 \%$ of children with absence epilepsy. $5 \%$ to $10 \%$ have a history of febrile seizures. The normal neurological findings, normal development, and normal MRI findings in this case exclude other underlying illnesses and indicate that the seizure disorder here is idiopathic. The seizure history, the EEG findings, and the idiopathic nature of the disorder point to the diagnosis of childhood absence epilepsy.

- Example 2: The parents of an otherwise healthy and normally developed 5-year-old girl were awakened in the night by gurgling noises produced by their daughter. They found the child in bed with twitching of all four limbs. She had urinated during the seizure; immediately afterward, she was still salivating to an increased degree and her speech was slurred. By the time the child was examined in the hospital a short while later, the only neurologic finding was mild weakness of the left arm, which resolved completely within an hour. EEG revealed normal baseline activity and a high-amplitude sharpslow-wave focus with 5 phases in the right centrotemporal area that was markedly activated by sleep. An MRI scan of the brain was normal.

The seizure described by the parents is typical of a (secondarily) generalized tonic-clonic seizure. The seizure symptomatology, in combination with the EEG findings with respect to the localization, configuration, and activation of the epilepsy-typical potentials in sleep, and along with the normal MRI scan and normal findings on neurological examination, suggests the diagnosis of benign idiopathic partial epilepsy (rolandic epilepsy). The transient postictal weakness (Todd's paresis) suggests a focal seizure origin, as do the EEG findings. Todd's paresis is seen after about $10 \%$ of rolandic seizures.

- Example 3: A twelve-year-old boy was presented to us because of episodes of pallor, salivation, and unresponsiveness to speech that had been occurring over the past two months. The episodes lasted about five minutes each and began with a strange feeling in the area of the stomach, accompanied by fear. The family had also noticed that the boy had had difficulty finding words for several months. An EEG revealed mild slowing and rare sharp waves in the left temporal area, and an MRI scan revealed an area of hyperintense signal in the left temporal lobe. Video EEG monitoring was performed, and a seizure with onset in the left temporal lobe was recorded. The episodes described were well controlled preoperatively with anticonvulsant medication. The lesion was surgically removed, and histological examination confirmed the suspected diagnosis of a low-grade tumor. Postoperatively, the patient was free of seizures, and the anticonvulsant medication was successfully tapered to off. The neuropsychological findings remained entirely unchanged, or, in fact, slightly better after surgery.

The dominant seizure type here consisted of complex partial seizures whose manifestations were highly typical of (mesial) temporal lobe epilepsy. The speech disturbance during the seizures is an indication of the lateralization of seizures to the left (language-dominant) hemisphere. An MRI scan should always be performed to evaluate newly occurring focal epilepsy. In the case discussed, operative treatment with the techniques of epilepsy surgery (including intraoperative electrocorticography) resulted not only in complete removal of the tumor, but also in permanent freedom from seizures. 